\title{
Treatment of Peri-Implant Defects With Combination Growth Factor Cement
}

\author{
Stephen J. Meraw, ${ }^{*}$ Charles M. Reeve ${ }^{\dagger}$ Christine M. Lohse,${ }^{\dagger}$ and Tracy M. Sioussat $\$$
}

Background: The use of growth factor agents in the regeneration of oral tissues is an area of current investigation. Combinations of growth factors have been used synergistically to improve tissue regeneration. The aim of this study was to determine the effects of a combination growth factor cement (GFC) on guided bone regeneration around dental implants.

Methods: A combination of bone morphogenetic protein-2 (BMP-2), transforming growth factor- $\beta$ (TGF- $\beta$ ), platelet-derived growth factor (PDGF), and basic fibroblast growth factor (bFGF) was used in a bioabsorbable, non-hydroxyapatite, calcium phosphate cement. Five adult hound dogs were used to compare the effects of GFC, plain cement, and control (no cement). The right and left second, third, and fourth mandibular premolar teeth were extracted; the implant osteotomies were prepared; and a uniform circumferential gap was prepared $1.5 \mathrm{~mm}$ beyond the width of the implant in the coronal half of the osteotomy for cement placement. Titanium machine-polished dental implants were placed in the prepared sites, and coronal defects were treated according to previously randomized, assigned modality. A bioabsorbable collagen membrane was secured over the control site, and the flaps were closed primarily. The dogs were maintained on a soft diet to avoid soft tissue trauma. The dogs were sacrificed at 3 months. The specimens were sectioned, mounted, and stained with Stevenel's blue and van Gieson's picric fuchsin. The boneto-implant contact and bone $1 \mathrm{~mm}$ peripheral to the implant surface were recorded with a computerized microscopic digitizer.

Results: The findings of this study indicate a significant effect of GFC on increased bone-to-implant contact and amount of bone per surface area compared with the other treatment modalities $(P<0.0009)$. Plain cement demonstrated slight but nonsignificant increases compared with the control $(P>0.05)$.

Conclusions: GFC increases bone-to-implant contact and bone surface area within peri-implant defects. Further studies may be beneficial to determine the feasibility of its use for other regenerative applications. J Periodontol 2000;71:8-13.

\section{KEY WORDS}

Guided bone regeneration; growth factors, basic fibroblast; growth factors, platelet-derived; growth factors, transforming; dental implants.

\footnotetext{
* Currently, Department of Periodontics/Prevention/Geriatrics, University of Michigan School of Dentistry, Ann Arbor, MI; previously, Department of Dental Specialties, Section of Periodontics, Mayo Clinic and Mayo Foundation, Rochester, MN.

$\dagger$ Section of Periodontics, Mayo Clinic and Mayo Foundation.

$\neq$ Section of Biostatistics.

$\S$ Tissue Engineering Inc., Boston, MA.
}

$\mathrm{T}$ The improved success of dental implants has been an ongoing area of research. Improvement in dental implant wound healing is a current area of investigation, and use of biologic mediators to improve the quantity and quality of the supporting bone has shown promise. ${ }^{1-6}$ Of particular interest are the polypeptide growth and differentiation factors, which have been shown to help in the regulation and stimulation of the healing process. Growth factors have been found in healing wound tissues, bone, and cementum, ${ }^{7}$ and have been shown to enhance cell proliferation, differentiation, chemotaxis, and extracellular matrix synthesis. ${ }^{8-16}$

The use of several growth factors in periimplant bone healing has yielded improvements in bone-implant contact as well as rate of bone regeneration. ${ }^{2-6}$ The use of bovine bone morphogenetic protein (bBMP) in the preclinical model has been shown to increase the rate of formation of periimplant bone, in addition to bone-implant contact in early healing. ${ }^{5,6}$ Osteogenic protein (OP-1), platelet-derived growth factor (PDGF), and insulin-like growth factor-I (IGF-I) have also been shown to be influential in improving the regeneration of periimplant bone. ${ }^{2-4}$

Although the role and use of individual growth factors remain an area of study, the use of combinations of growth factors has shown synergistic improvements in healing. ${ }^{17-20}$ The use of a PDGF and IGF combination, as well as a PDGF and transforming growth factor-alpha (TGF- $\alpha$ ) combination, has resulted in synergistic effects in vivo. ${ }^{18,19}$ The use of growth factor com- 
binations to improve the healing response might further assist in the complex cellular events and interactions that normally occur during healing.

Several growth and differentiation factors have been identified during embryologic development of alveolar bone. ${ }^{21-23}$ Recently, a combination of BMP-2, TGF- $\beta$, basic fibroblast growth factor (bFGF), and PDGF has been isolated from embryologic tissues and shown to improve the mitogenic response of dermal fibroblasts and osteoblastic cells in vitro (unpublished observations). The combination was roughly 2 parts of TGF $\beta$ and bFGF by weight to 1 part BMP- 2 and PDGF. A similar 2:1 ratio was reported as optimal in the use of a PDGF-2 and IGF-I combination. ${ }^{18}$

The aim of this study was to examine the effects of a combination growth factor cement (GFC) on guided bone regeneration in the repair of peri-implant osseous defects. This model was chosen for the bioabsorbable cement to act as a carrier device for the sustained delivery of growth factors during osseous healing of peri-implant defects. The combination included BMP2 , TGF- $\beta$, bFGF, and PDGF, each of which has been shown to influence the healing response. ${ }^{24-39}$

\section{MATERIALS AND METHODS}

The GFC included (in $\mathrm{pg} / \mathrm{mg}$ of cement) approximately $1.2 \mathrm{pg}$ TGF- $\beta, 1.2 \mathrm{pg}$ bFGF, $0.5 \mathrm{pg}$ BMP-2, and 0.6 pg PDGF, or roughly a $2: 1$ combination of TGF $-\beta$ and bFGF to BMP-2 and PDGF, respectively." These factors were obtained through purification of developing porcine oral tissues. In each defect, approximately 60 $\mathrm{mg}$ of cement was used. Previous in vitro testing verified the biologic activity of the growth factors to stimulate the proliferation of osteoblasts to numbers $50 \%$ over control cell numbers after 4 days in culture, and the ability of the cement to set, which had a working time of approximately 7 minutes.

Five adult male hound dogs were used because the jaw size was adequate for endosteal implant placement. This study was approved by the Institutional Animal Care and Use Committee of Mayo Foundation. Thirty titanium machine-polished implants "ll were used and distributed evenly among 3 treatment groups: GFC, plain cement, and control. There were 3 implants per mandible side, with 10 implants per treatment variable.

Each dog was given $4 \%$ thiamylan sodium (20 $\mathrm{mg} / \mathrm{kg}$ ) intravenously. ${ }^{\#}$ The animals were intubated after induction of general anesthesia and maintained with $1 \%$ halothane inhalational anesthetic together with a $50 \%$ mixture of nitrous oxide and oxygen. The surgical sites were disinfected with a sterile swab of povidone-iodine and anesthetized locally with $2 \%$ lidocaine $\mathrm{HCl}$ with $1: 100,000$ epinephrine for improved hemostasis and postoperative analgesia. Full-thickness mucoperiosteal flaps were incised and reflected on the facial and lingual aspects of the teeth to be extracted. The second, third, and fourth mandibular premolar teeth were extracted bilaterally as atraumatically as possible by midcoronal facial-to-lingual sectioning with a high-speed handpiece with a sterile water-cooled bur and standard dental forceps. After odontectomy, alveoloplasty was performed on the remaining alveolar ridge for improved form and elimination of bony spicules before implant placement. Next, standard implant osteotomy preparations were performed with sterile water cooling in the residual alveolus area. The coronal half of the implant preparation was widened to $5.25 \mathrm{~mm}$ with a trephine bur.

Three endosteal dental implants of $3.75 \mathrm{~mm}$ width and $8 \mathrm{~mm}$ length were surgically placed in each side of the mandible (Fig. 1), according to previously randomized, assigned modality. Cover screws were placed to cover the implants. A bioabsorbable collagen membrane** was placed over the "no cement" control sites to allow a space for bony ingrowth and prevent soft tissue ingrowth, ${ }^{40}$ since the cement in the other groups acted as a barrier for soft tissue ingrowth, serving this purpose. The cement groups did not receive a membrane because the hardened cement acted as its own barrier. The membranes were secured in place with bone tacks ${ }^{\dagger \dagger}$ to prevent movement of the membrane. The cement treatments were prepared and packed into the $0.75 \mathrm{~mm}$ circumferential defects according to previously randomized, assigned modality. Surgical flaps were reapproximated and closed primarily with 4-0 polyglactin 910 sutures.

Postoperatively, butorphanol ${ }^{\ddagger}$ (0.2 to $0.4 \mathrm{mg} / \mathrm{kg}$ every 2 to 5 hours) was administered intramuscularly as needed for discomfort, and a 300,000 IU/ml preparation of penicillin $G$ benzathine and penicillin $G$ procaine ${ }^{\S}(1 \mathrm{ml} / 5$ to $10 \mathrm{~kg}$ ) was given intramuscularly to reduce the potential for infection. The dogs were kept in the recovery room until they overcame the effects of general anesthesia and their condition was stable. For the rest of the study, they were fed a soft diet $^{\|\|}$to reduce potential trauma to the surgical sites.

Histologic examination occurred after a 3-month healing period. This period was chosen to evaluate any differences after a standard healing period. ${ }^{41}$ The dogs were euthanized as scheduled with an overdose of sodium pentobarbital, and mandible specimens collected with the use of a band saw. Following collection, specimens were fixed, sectioned, and mounted as previously described. ${ }^{1}$ All specimens were then

\footnotetext{
\| Bone-derived ADMAT, Tissue Engineering, Inc., Boston, MA.

I Brånemark, Nobel Biocare, Westmont, IL.

\# Surital, Parke-Davis Co., Detroit, MI.

** Biomend, Calcitek, Carlsbad, CA

$\dagger \dagger$ IMTEC, Ardmore, OK

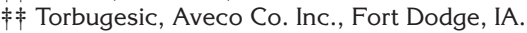

$\S \S$ Flo-Cillin, Fort Dodge Laboratories, Inc., Fort Dodge, IA.

\|I Science Diet, Hill's Pet Nutrition, Inc., Topeka, KS.
} 

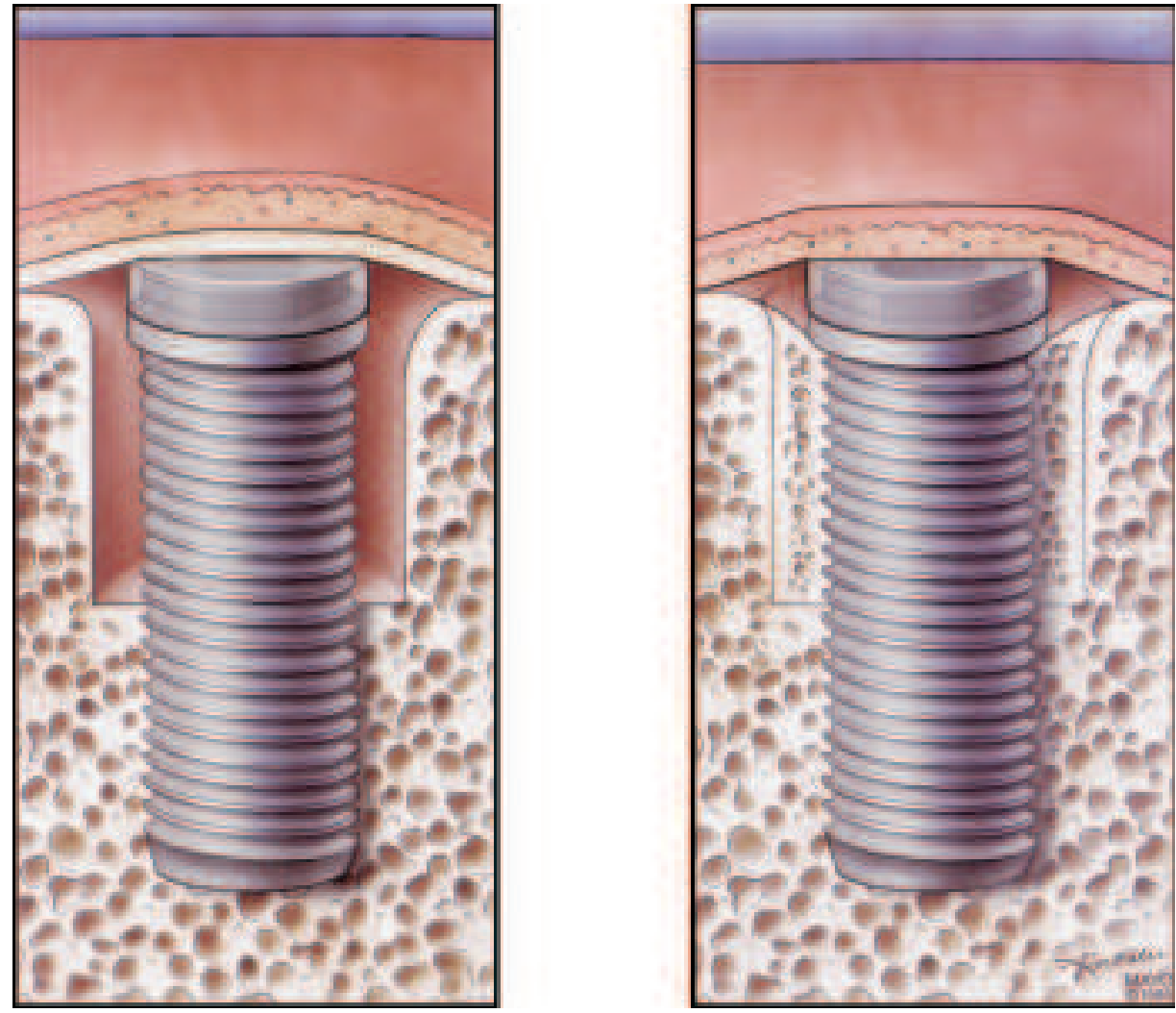

Figure I.

Implant placement with circumferential coronal defect on the left. Bone regeneration post-healing on the right.

coded prior to analysis so that the examiner was unaware of the treatment group, to allow for a blinded examination.

Histologic specimens were examined with transmitted light at a magnification of $\times 100$. The implant and peri-implant tissues, including bone-implant contact and amount of bone per area, were analyzed with the use of a semi-automated computerized technique, $\mathbb{\text { IT }}$ in which a microscope was interfaced with a computer and digitizer. The bone-implant contact was traced with the digitizer and recorded as a value, which was converted

Table I.

Bone-Implant Contact

\begin{tabular}{lcccc}
\hline \multicolumn{5}{c}{ Bone-Implant Contact (\%) } \\
\hline Treatment & Mean & SD & Minimum & Maximum \\
\hline GFC & 77.4 & 7.2 & 67.5 & 87.8 \\
PC & 59.7 & 12.6 & 32.1 & 75.6 \\
Control & 54.8 & 12.3 & 27.9 & 67.6 \\
\hline
\end{tabular}

GFC, growth factor cement; PC, plain cement. to a percentage of bone in contact with the implant surface. The amount of bone per area in each field $(0.507$ $\mathrm{mm}^{2}$ ) was traced with the digitizer and recorded as an area value, 2 fields from the implant surface, along the length of the implant. This value was then converted to a mean percentage of the total area per field.

\section{Statistical Analysis}

The primary response variables were the percentage of the length of the implant section in contact with bone and the percentage of bone per area, as measured by histologic examination. Treatment effects were evaluated using an analysis of variance (ANOVA) mixed model with terms for animal, position, side, and treatment, with animal handled as a random effect. Least-squares means were estimated to account for the imbalance in the study design resulting from 4 measurements not being available (all 3 treatments on the right side of one animal and one treatment on the right side of another animal). Pairwise differences of the least-squares means using the corresponding standard errors were assessed with $t$ tests. All $P$ values were 2 -sided, and a type I error level of 0.05 was used.

\section{RESULTS}

The results for the histomorphometric data are summarized in Tables 1 and 2. The primary response variables were percentage of bone-implant contact and percentage of peripheral bone per area, as measured histologically.

Iๆ BQ System IV Program, REM Biometrics, Inc., Nashville, TN.

Table 2.

Bone Per Area

\begin{tabular}{lcccc}
\hline \multicolumn{5}{c}{ Bone Per Area (\%) } \\
\hline Treatment & Mean & SD & Minimum & Maximum \\
\hline GFC & 76.8 & 3.7 & 70.9 & 81.0 \\
PC & 67.4 & 6.2 & 57.4 & 76.5 \\
Control & 64.0 & 4.2 & 57.3 & 68.2 \\
\hline
\end{tabular}

GFC, growth factor cement; PC, plain cement. 


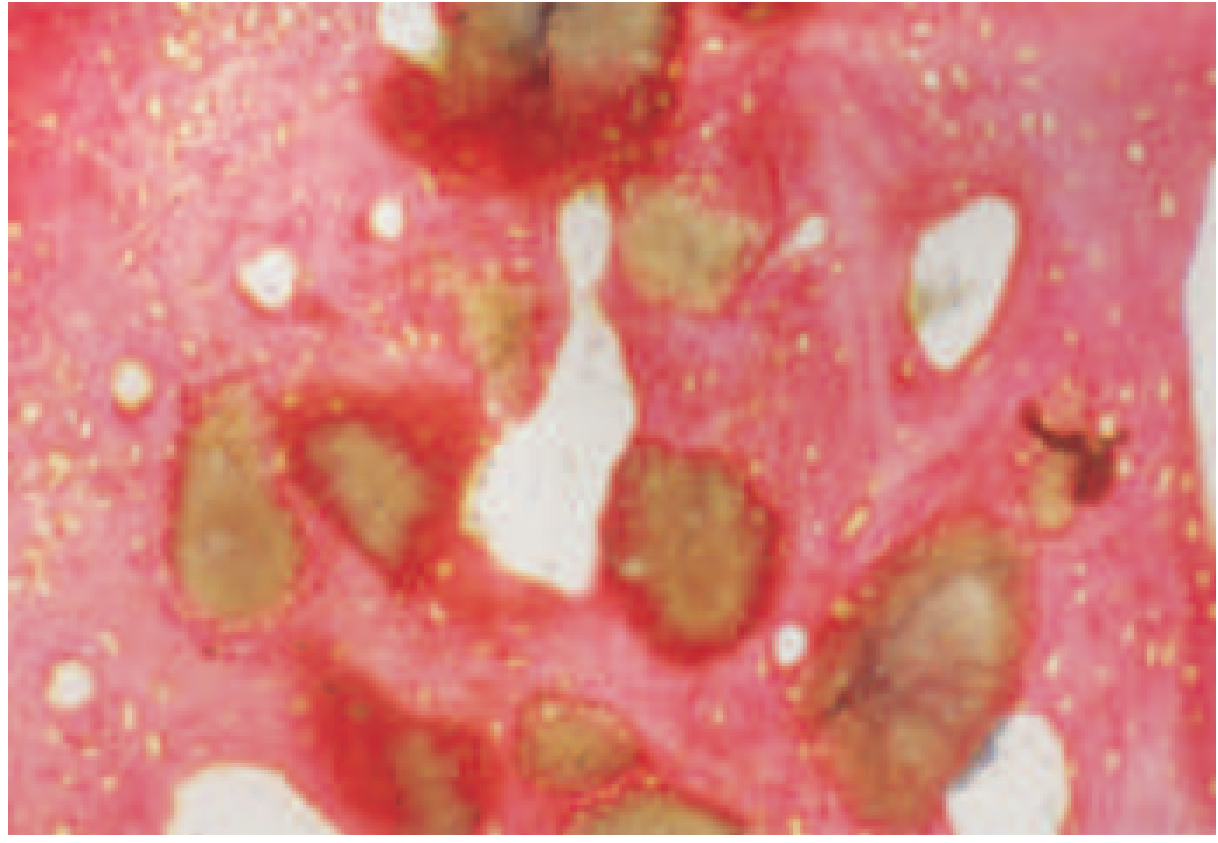

Figure 2.

Residual cement particles (Stevenel's blue and van Gieson's picric fuchsin stain; ×200). groups and 8 implants in the control group for comparisons. No exposures were encountered with the remaining implants.

For mean percentage of boneto-implant contact, GFC demonstrated a $17.7 \%(P=0.0008)$ and 22.6\% $(P<0.0001)$ improvement over plain cement and the control, respectively (Table 1 ). The plain cement demonstrated a mean improvement of $4.9 \%$ over the control; however, this difference was not significant $(P=$ $0.12)$.

For mean percentage of peripheral bone per area, GFC had the greatest effect (Table 2). An improvement of $9.4 \%$ was demonstrated over plain cement $(P=$ $0.0009)$ and $12.8 \%$ over the control $(P<0.0001)$. A difference of $3.4 \%$ was seen between plain cement and control, but this was not significant $(P=0.12)$.

Of the 30 implants, 3 were lost in a dog that had an abnormal chewing habit on one side of the mandible; there was one implant in each treatment group. One additional implant in the control group was lost as a result of processing error. There were 9 implants per group in the GFC and plain cement

\section{DISCUSSION}

The present study examined the effects of a combination growth factor cement on bone regeneration in peri-implant defects. Evaluation of the effects involved histometric analysis of the bone-implant contact and peripheral implant supporting bone, up to $1 \mathrm{~mm}$ from
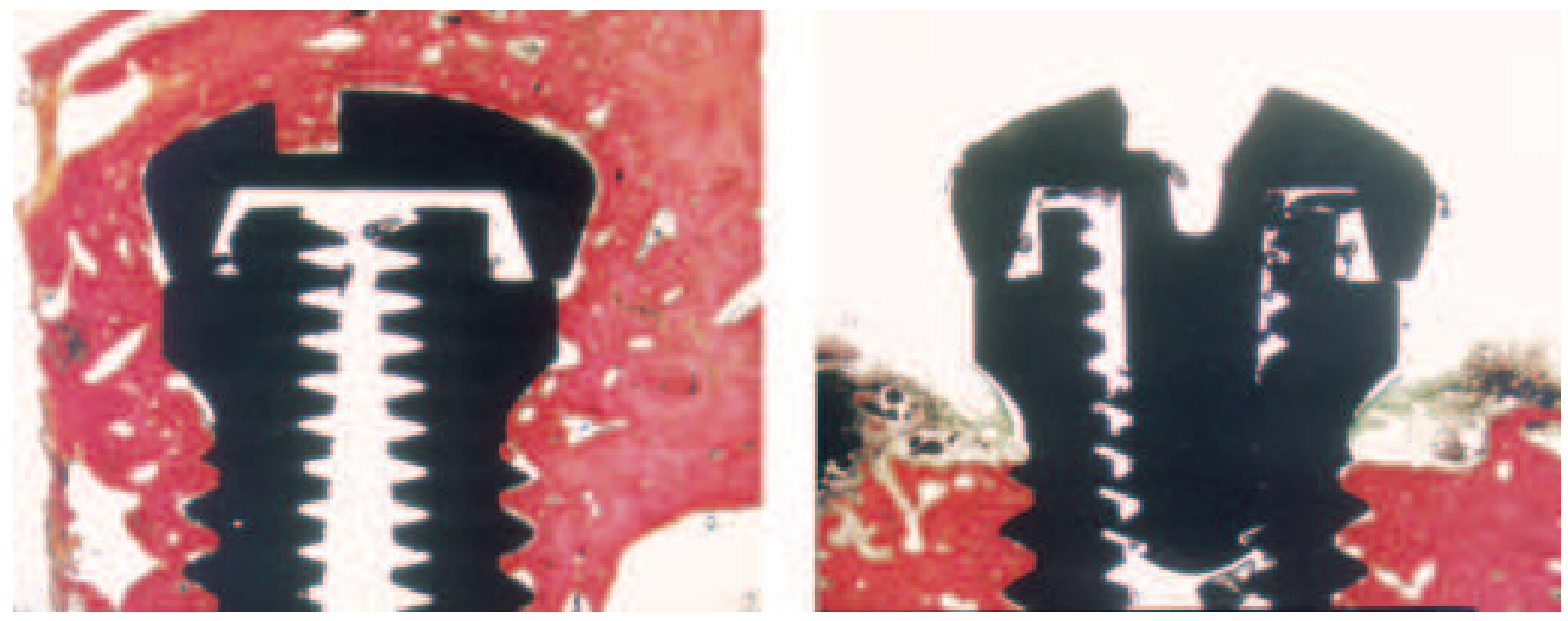

Figure 3.

Coronal portion of the implant. Osseous overgrowth on the left GFC specimen, and normal osseous level on the right control specimen (Stevenel's blue and van Gieson's picric fuchsin stain; ×20). 
the threaded surface, after a 3-month healing period. The bioabsorbable non-hydroxyapatite calcium phosphate cement was completely replaced by bone along the implant surfaces. However, in a few slides, some residual cement particles were present superior to the implants. The particles were incorporated within bone, without evidence of soft tissue encapsulation, and not surrounded by inflammatory cells (Fig. 2). Therefore, the cement was well tolerated.

The use of GFC resulted in an improvement of both the bone-implant contact and the amount of peripheral bone per area. Because this is the first test of this growth factor combination with this vehicle, we are unable to make direct comparisons to previous studies. However, other combinations have been studied with peri-implant bone healing. Becker et al. ${ }^{3}$ found a $17.9 \%$ improvement in bone-implant contact after 18 weeks of healing with a PDGF/IGF-I combination compared to ePTFE membrane alone. Lynch et al. ${ }^{4}$ found an $8.7 \%$ increase in bone-implant contact in early healing with a PDGF-B/IGF-I combination. The difference between test and control groups eventually became much smaller and non-significant in later healing. In terms of peripheral peri-implant bone, Becker et al. found a $26.5 \%$ improvement after 18 weeks, while Lynch et al. found a $26.8 \%$ improvement in the test group compared with the control at 3 weeks of healing. ${ }^{3,4}$ This difference is larger than the $12.8 \%$ improvement of our GFC over the control, which can be attributed to increased amounts of bone in our control group. Of particular interest is the combination dosage used in this study; it was much smaller than the dosages of $5 \mu \mathrm{g}$ and $4 \mu \mathrm{g}$ for the Becker et al. and Lynch et al. studies, respectively.

The use of polypeptide growth and differentiation factors has been shown to improve implant-supporting bone. Combinations of growth factors might be of extended benefit over single growth factor use in early bone healing, which may address the complexity of the required cellular events and interactions that normally occur in the healing process. The particular combination used in this study actually induced bone growth beyond the cover screw of a few test implants (Fig. 3). This goes beyond the biologic activity usually seen in implant healing, in which the crestal bone height is usually maximally at the level of polished collar or first thread. ${ }^{42}$ Further studies would be helpful to explore other applications of GFC, in addition to improvements of implant-supporting bone.

\section{ACKNOWLEDGMENTS}

We thank Dr. Michael Rohrer, Tom Sprowl, Hari Prasad, and Paul Lopolito for technical assistance, and Tissue Engineering and Nobel Biocare for material support. We also thank the Mayo Foundation for financial support. Tracy Sioussat is employed as a research scientist at Tissue Engineering Inc.

\section{REFERENCES}

1. Meraw SJ, Reeve CM, Wollan PC. Use of alendronate in peri-implant defect regeneration. J Periodontol 1999; 70:151-158.

2. Rutherford RB, Sampath TK, Rueger DC, Taylor TD. Use of bovine osteogenic protein to promote rapid osseointegration of endosseous dental implants. Int J Oral Maxillofac Implants 1992;7:297-301.

3. Becker W, Lynch SE, Lekholm U, et al. A comparison of ePTFE membranes alone or in combination with platelet-derived growth factors and insulin-like growth factor-I or demineralized freeze-dried bone in promoting bone formation around immediate extraction socket implants. J Periodontol 1992;63:929-940.

4. Lynch SE, Buser D, Hernandez RA, et al. Effects of the platelet-derived growth factor/insulin-like growth factorI combination on bone regeneration around titanium dental implants. Results of a pilot study in beagle dogs. $J$ Periodontol 1991;62:710-716.

5. Xiang W, Baolin L, Yan J, Yang X. The effect of bone morphogenetic protein on osseointegration of titanium implants. J Oral Maxillofac Surg 1993;51:647-651.

6. Xiang W, Yan J, Baolin L, et al. Tissue reactions to titanium implants containing bovine bone morphogenetic protein: A scanning electron microscopic investigation. Int J Oral Maxillofac Surg 1994;23:115-119.

7. The American Academy of Periodontology. The potential role of growth and differentiation factors in periodontal regeneration (position paper). J Periodontol 1996;67:545-553.

8. Carpenter G, Cohen S. Human epidermal growth factor and the proliferation of human fibroblasts. J Cell Physiol 1975;88:227-238.

9. Roberts AB, Anzano MA, Wakefield LM, Roche NS, Stern DF, Sporn MB. Type $\beta$ transforming growth factor: A bifunctional regulator of cellular growth. Proc Natl Acad Sci (USA) 1985;82:119-123.

10. Gospodarowicz D, Moran JS, Braun DL. Control of proliferation of bovine vascular endothelial cells. J Cell Physiol 1977;91:377-386.

11. Deul TF, Senior RM, Huang JS, Griffin GL. Chemotaxis of monocytes and neutrophils to platelet-derived growth factor. J Clin Invest 1982;69:1046-1049.

12. Seppa H, Grotendorst G, Seppa S, Schiffman E, Martin GR. Platelet-derived growth factor is chemotactic for fibroblasts. J Cell Biol 1982;92:584-588.

13. Wahl SM, Hunt DA, Wakefield LM, et al. Transforming growth factor beta induces monocyte chemotaxis and growth factor production. Proc Natl Acad Sci (USA) 1987;84:5788-5792.

14. Chua CC, Geiman DE, Keller GH, Ladda RL. Induction of collagenase secretion in human fibroblasts by growth promoting factors. J Biol Chem 1985;260:5213-5216.

15. Roberts AB, Sporn MB, Assoian RK, et al. Transforming growth factor type $\beta$ : Rapid induction of fibrosis and angiogenesis in vivo and stimulation of collagen formation in vitro. Proc Natl Acad Sci (USA) 1986;83:41674171.

16. Savage K, Siebert E, Swann D. The effect of plateletderived growth factor on cell division and glycosaminoglycan synthesis by skin and scar fibroblasts. J Invest Dermatol 1987;89:93-99.

17. Lynch SE, Nixon JC, Colvin RB, Antoniades HN. Role of platelet-derived growth factor in wound healing: Synergistic effects with other growth factors. Proc Natl Acad Sci (USA) 1987;84:7696-7700.

18. Lynch SE, Colvin RB, Antoniades HN. Growth factors in wound healing. Single and synergistic effects on partial 
thickness porcine skin wounds. J Clin Invest 1989; 84:640-646.

19. Greenhalgh DG, Hummel RP III, Albertson S, Breeden MP. Synergistic actions of platelet-derived growth factor and the insulin-like growth factors in vivo. Enhancement of tissue repair in genetically diabetic mice. Wound Rep Reg 1993;1:69-81.

20. Knighton DR, Fiegel VD, Austin LL, Ciresi KF, Butler EL. Classification and treatment of chronic nonhealing wounds. Successful treatment with autologous plateletderived wound healing factors (PDWHF). Ann Surg 1986;204:322-329.

21. Heikinheimo K. Stage-specific expression of decapentaplegic-Vg-related genes 2, 4, and 6 (bone morphogenetic proteins 2, 4, and 6) during human tooth morphogenesis. J Dent Res 1994;73:590-597.

22. Jones CM, Lyons KM, Hogan BL. Involvement of bone morphogenetic protein-4 (BMP-4) and Vgr-1 in morphogenesis and neurogenesis in the mouse. Development 1991;111:531-542.

23. Lyons KM, Pelton RW, Hogan BL. Organogenesis and pattern formation in the mouse: RNA distribution patterns suggest a role for bone morphogenetic protein 2A (BMP. 2A). Development 1990;109:833-844.

24. Toriumi DM, Kotler HS, Luxenberg DP, Holtrop ME, Wang EA. Mandibular reconstruction with a recombinant boneinducing factor. Arch Otolaryngol Head Neck Surg 1991;17:1101-1112.

25. Sigurdsson TJ, Lee MB, Kubota K, Turek TJ, Wozney JM, Wikesjo UME. Periodontal repair in dogs: Recombinant human bone morphogenetic protein-2 significantly enhances periodontal regeneration. J Periodontol 1995; 66:131-138.

26. Howell TH, Fiorellini J, Jones A, et al. A feasibility study evaluating rhBMP-2/absorbable collagen sponge device for local alveolar ridge preservation or augmentation. Int J Periodontics Restorative Dent 1997;17:125-139.

27. Urist MR, DeLange RJ, Finerman GA. Bone cell differentiation and growth factors. Science 1983;220:680 686.

28. Dennison DK, Vallone DR, Pinero GJ, Rittman B, Caffesse RG. Differential effect of TGF- $\beta 1$ and PDGF on proliferation of periodontal ligament cells and gingival fibroblasts. J Periodontol 1994;65:641-648.

29. Centrella M, McCarthy TL, Canalis E. Transforming growth factor beta is a bifunctional regulator of replication and collagen synthesis in osteoblast-enriched cell cultures from fetal rat bone. J Biol Chem 1987;262:28692874.

30. Keski-Oja J, Raghow R, Sawdy M, et al. Regulation of the mRNAs for type I plasminogen activator inhibitor, fibronectin, and type I procollagen by transforming growth factor- $\beta$. Divergent responses in lung fibroblasts and carcinoma cells. J Biol Chem 1988;263:3111-3115.

31. Wrana JL, Macho M, Hawrylyshyn B, Yao KL, Domenicucci C, Sodek J. Differential effects of transforming growth factor- $\beta$ on the synthesis of extracellular matrix proteins by normal fetal rat calvarial bone cell populations. J Cell Biol 1988;106:915-924.
32. Terranova VP, Odziemiec C, Tweden KS, Spadone DP. Repopulation of dentin surfaces by periodontal ligament cells and endothelial cells: Effect of basic fibroblast growth factor. J Periodontol 1989;60:293-301.

33. Canalis E, McCarthy T, Centrella M. Effects of basic fibroblast growth factor on bone formation in vitro. $J$ Clin Invest 1988;81:1572-1577.

34. Folkman J, Klagsbrun M. Angiogenic factors. Science 1987;235:442-447.

35. Howes R, Bowness JM, Grotendorst GM, Marting GR, Reddi AH. Platelet-derived growth factor enhances demineralized bone matrix-inducing cartilage and bone formation. Calcif Tissue Int 1988;42:34-38.

36. Hughes FJ, Aubin JE, Heersche JN. Differential chemotactic responses of different populations of fetal rat calvaria cells to platelet-derived growth factor and transforming growth factor beta. Bone Miner 1992;19:63-74.

37. Nash TJ, Howlett CR, Martin C, Steele J, Johnson KA, Hicklin DJ. Effect of platelet-derived growth factor on tibial osteotomies in rabbits. Bone 1994;15:203-208.

38. Giannobile WV, Whitson SW, Lynch SE. Synergistic effects of insulin-like growth factor-I (IGF-I) with other growth factors on bone formation in vitro. $J$ Dent Res 1994;73(Spec. Issue):205(Abstr. 831).

39. Hurley LA, Stinchfield FE, Bassett AL, Lyon WH. The role of soft tissues in osteogenesis: An experimental study of canine spine fusions. J Bone Joint Surg 1959;41A:12431254 .

40. Brånemark PI. Osseointegration and its experimental background. J Prosthet Dent 1983;50:399-410.

41. Albrektsson T, Jansson T, Lekholm U. Osseointegrated dental implants. Dent Clin North Am 1986;30:151-174.

42. Adell R. Long-term treatment results. In: Brånemark PI, Zarb GA, Albrektsson T, eds. Tissue-Integrated Prostheses. Osseointegration in Clinical Dentistry. Chicago: Quintessence Publishing Company; 1985:10.

Send reprint requests to: Dr. Stephen J. Meraw, Dept. of Periodontics/Prevention/Geriatrics, University of Michigan School of Dentistry, 1011 N. University Ave., Ann Arbor, MI 48109.

Accepted for publication May 4, 1999. 